\title{
Fluorescence Characteristics of Humic Acid in Chinese Black Soil under Long-Term Fertilization
}

\author{
Dan Wei, ${ }^{1}$ Yan Li, ${ }^{2,3}$ Shan-shan Cai, ${ }^{2,4}$ Liang Jin, ${ }^{2}$ Yu-mei Li, ${ }^{2}$ Wei Wang, \\ Yang Bai, ${ }^{3} \mathrm{Yu} \mathrm{Hu},{ }^{3}$ and Nicholas Clarke $\oplus^{5}$ \\ ${ }^{1}$ Institute of Plant Nutrition and Resources, Beijing Academy of Agriculture and Forestry Sciences, Beijing 100097, China \\ ${ }^{2}$ Institute of Soil Fertilizer and Environment Resources, Heilongjiang Academy of Agricultural Sciences, Harbin 150086, China \\ ${ }^{3}$ College of Resources and Environment, Northeast Agricultural University, Harbin 150030, China \\ ${ }^{4}$ College of Land and Environment, Shenyang Agricultural University, Shenyang 110866, China \\ ${ }^{5}$ Norwegian Institute of Bioeconomy Research, P.O. Box 115, 1431 Ås, Norway
}

Correspondence should be addressed to Nicholas Clarke; nicholas.clarke@nibio.no

Received 22 April 2019; Revised 11 June 2019; Accepted 15 July 2019; Published 7 August 2019

Guest Editor: Chongyang Shen

Copyright (C) 2019 Dan Wei et al. This is an open access article distributed under the Creative Commons Attribution License, which permits unrestricted use, distribution, and reproduction in any medium, provided the original work is properly cited.

\begin{abstract}
Humic substances are important indicators of soil fertility. The fluorescence properties of humic acids from black soils in Harbin, northeast China, were investigated, after long-term fertilization using treatments with or without mineral fertilizer (NPK) and organic manure. Excitation and emission matrices combined with parallel factor analysis were used to investigate the structure of the humic acid. Principal component analysis was performed to select the most suitable parameters for the description of humic acid. The dimension reduction for the original fluorescence parameters extracted two principal components. By using the two principal component scores as a new index for clustering, it was concluded that long-term fertilization treatments in black soil in Harbin clustered into three groups of manure + NPK and organic manure treatments, NPK treatment, and soil without any fertilization. Manure + NPK fertilization and manure fertilization alone led to a higher degree of humification than NPK only or the control. We conclude that long-term fertilization with organic matter with or without NPK could increase the humification degree of these soils.
\end{abstract}

\section{Introduction}

Humic substances are among the most important indicators of soil fertility, affecting the physical, chemical, and biological characteristics of the soil [1-3]. Humic materials in soil are considered to be the result of a physicochemical copolymerization of compounds derived from diverse sources (e.g., proteins, lignins, and plant and microbial metabolites). Humic substances can be separated into several components under different $\mathrm{pH}$ conditions. Humic acid is defined as the portion of humic substances which is soluble in dilute alkali and insoluble in dilute acid. Humic acids are a natural polymer, resulting from decomposition of organic matter; particularly plants are natural constituents of soil. Humic acid has complex chemical properties; the molecular weight of this substance is around 5000 to 100000 daltons [4]. The composition, structure, and properties of humic acid are directly related to soil fertility and crop yield [5]. Previous studies on long-term fertilization of black soil showed that the combined application of organic fertilizer and chemical fertilizer was beneficial to increase the number of microorganisms and enzyme activities in black soil, followed by the single application of organic fertilizer. The combined application of organic fertilizer and chemical fertilizer may lead to a decrease in the number of nitrogen-fixing bacteria. $[6,7]$. Long-term combined application of organic fertilizer and chemical fertilizer was beneficial to the accumulation of soil organic matter and the increase of soil humic acid content $[8,9]$. Wang et al. [10] suggested that long-term application of organic fertilizer made the molecular structure of humic acid simpler and increased the humic acid activity and its simple fractions. The results of application of mineral fertilizer were 
the opposite. Long-term fertilization may influence the content and structure of humic acid. However, the relationship between different fertilization methods and composition of humic acid, in particular humic acid structure of black soil under long-term fertilization, still need further research. This study comprehensively evaluated the effect of different fertilization methods on the structure of humic acid in black soil of northeastern China. In this study, excitation and emission matrix-parallel factor (EEM-PARAFAC) analysis was employed to investigate the fluorescence properties of humic acid. Principal component analysis (PCA) was used to select key parameters related to the structure of humic acid, which can transform a set of potentially correlated variables to a set of linearly uncorrelated variables without simultaneously losing the original variables $[11,12]$. Further, clustering analysis was used to distinguish the effects of different fertilization methods on humic acids. This comprehensive evaluation method might be helpful in identifying the optimum fertilization method with regard to effects on humic acid structure and function in black soil in northeastern China.

\section{Materials and Methods}

2.1. Study Site. The experimental site was located in Harbin, Heilongjiang Province, northeastern China $\left(45.44^{\circ} \mathrm{N}\right.$, $\left.126.39^{\circ} \mathrm{E}\right)$. The climate in this area is temperate continental monsoon climate with a mean annual temperature of $4.2^{\circ} \mathrm{C}$ and mean annual precipitation of $532 \mathrm{~mm}$. The soil samples were collected in the key field scientific observation experimental station on black soil ecological environment of the Ministry of Agriculture, Harbin, which was established in 1979. These black soils are phaeozems according to the WRB soil classification.

2.2. Experimental Design. This experiment included four fertilization treatments: control treatment (CK): soil without any fertilization; mineral NPK fertilization treatment (NPK): soil with only NPK fertilizer; organic manure treatment $(\mathrm{OM})$ : soil with only manure application; and manure + NPK fertilization treatment (MNPK): soil with NPK fertilizer and manure. In the NPK and MNPK treatments, soils were supplied with $150 \mathrm{~kg} \mathrm{ha}^{-1} \mathrm{~N}, 75 \mathrm{~kg} \mathrm{ha}^{-1} \mathrm{P}_{2} \mathrm{O}_{5}$, and 75 $\mathrm{kg} \mathrm{ha}{ }^{-1} \mathrm{~K}_{2} \mathrm{O}$. In the OM and MNPK treatments, horse manure provided $75 \mathrm{~kg} \mathrm{ha}^{-1} \mathrm{~N}\left(18600 \mathrm{~kg}\right.$ manure ha $\left.{ }^{-1}\right)$. The treatments were randomly arranged with three replicates; each plot included 8 rows that were $6 \mathrm{~m}$ in length with row spacing of $70 \mathrm{~cm}$. The cropping system was wheatmaize-soybean rotation since 1979, with the first crop having been soybean. Fertilizer was applied for every period of a wheat-maize-soybean rotation and incorporated into the soil immediately following application. Surface soil samples in the 0-20 cm layer were collected after harvest from 2003 to 2013.

2.3. Extraction and Determination of Humic Acid. The humic acid was extracted following the method of $\mathrm{Wu}$ et al. [13]. Briefly, $2 \mathrm{~g}$ sample was mixed with solution of $0.1 \mathrm{M}$ $\mathrm{Na}_{4} \mathrm{P}_{2} \mathrm{O}_{7} \cdot 10 \mathrm{H}_{2} \mathrm{O}$ and $0.1 \mathrm{M} \mathrm{NaOH}$ at $1: 10$ (w:v) with shaking for $24 \mathrm{~h}$ with rotational speed $200 \mathrm{rpm}$. After centrifugation
(11,000 $\mathrm{rpm} / 15 \mathrm{~min})$, the supernatant was filtered through a $0.45 \mu \mathrm{m}$ millipore membrane. The separation of humic acids was as follows: the $\mathrm{pH}$ of the supernatant was adjusted to 1.5 with $6 \mathrm{M} \mathrm{HCl}$ and the sample was allowed to stand for $12 \mathrm{~h}$ at $4^{\circ} \mathrm{C}$. The humic acid was then separated by centrifugation at $11,000 \mathrm{rpm}$ for $15 \mathrm{~min}$ to separate the supernatant from the precipitate which was humic acid. The obtained humic acid was washed with $0.1 \mathrm{M} \mathrm{HCl}$ deionized water several times and then dissolved with $0.05 \mathrm{M} \mathrm{NaHCO}_{3}$. The total organic carbon (TOC) of the humic acid was analysed by TOC analyser (N/C 2100, Jena Company of Germany). All the analyses were carried out in triplicate and the mean value was calculated for each case.

2.4. Fluorescence Characteristic Parameter Selection and Statistical Treatment. The fluorescence characteristics of humic acid were measured using a Luminescence Spectrometer LS50B (Perkin Elmer, Waltham, MA, USA). According to Cui et al. [14], the concentration of humic acid was diluted to identical levels of $10 \mathrm{mg} / \mathrm{L}$ to reduce the effect of varying humic acid concentrations among the samples on contribution to fluorescence intensities and inner filter effect. The emission wavelength over the range $250-600 \mathrm{~nm}$ was collected in $2 \mathrm{~nm}$ increments, while the excitation wavelength increased gradually from 200 to $550 \mathrm{~nm}$ in $10 \mathrm{~nm}$ increments. The scan speed was $2400 \mathrm{~nm}$ min-1. Parallel factor analysis (using the PARAFAC model) was carried out in MATLAB 2013a with the DOMFLuor toolbox. With reference to previous research results [15], some fluorescence characteristic parameters were selected to assess the humification degree of the four treatments: the fluorescence index f450/500, representing the ratio of emission intensity at $450 \mathrm{~nm}$ and $500 \mathrm{~nm}$ at $370 \mathrm{~nm}$ excitation; I436/I383, representing the ratio of fluorescence intensity at $436-383 \mathrm{~nm}$; the ratio of fluorescence intensity at 454-399 nm I454/I399 was calculated from the spectra in the synchronous-scan excitation mode acquired; the emission band between 308 and $363 \mathrm{~nm}$ is referred to as the fulvic-like region (FLR), and the emission band between 363 and $595 \mathrm{~nm}$ as the humic-like region (HLR); the humification index A4/A1 was the ratio of the last quarter to the first quarter in the emission spectrum of 370$600 \mathrm{~nm}$, whereas the $(\mathrm{C} 2+\mathrm{C} 3) / \mathrm{C} 1$ was the ratio of PARAFAC components, where $\mathrm{C} 1$ represents a protein-like substance, $\mathrm{C} 2$ represents a humic-like component, and C3 a xenobiotic component [16].

2.5. Statistical Analysis. These fluorescence characteristic parameters were analysed using PCA and cluster analysis with SPSS 19.0 software (IBM, USA). The humic acid dynamics and the humification degree were analysed by Origin Pro 2015. EEM-PARAFAC analysis was used to acquire detailed information about the humic acid characterization.

\section{Results and Discussion}

3.1. The Structural Characteristics of Humic Acid. The PARAFAC model is based on split-half analysis and residual analysis. Three fluorescent components under different treatments were identified by the PARAFAC model. As shown 

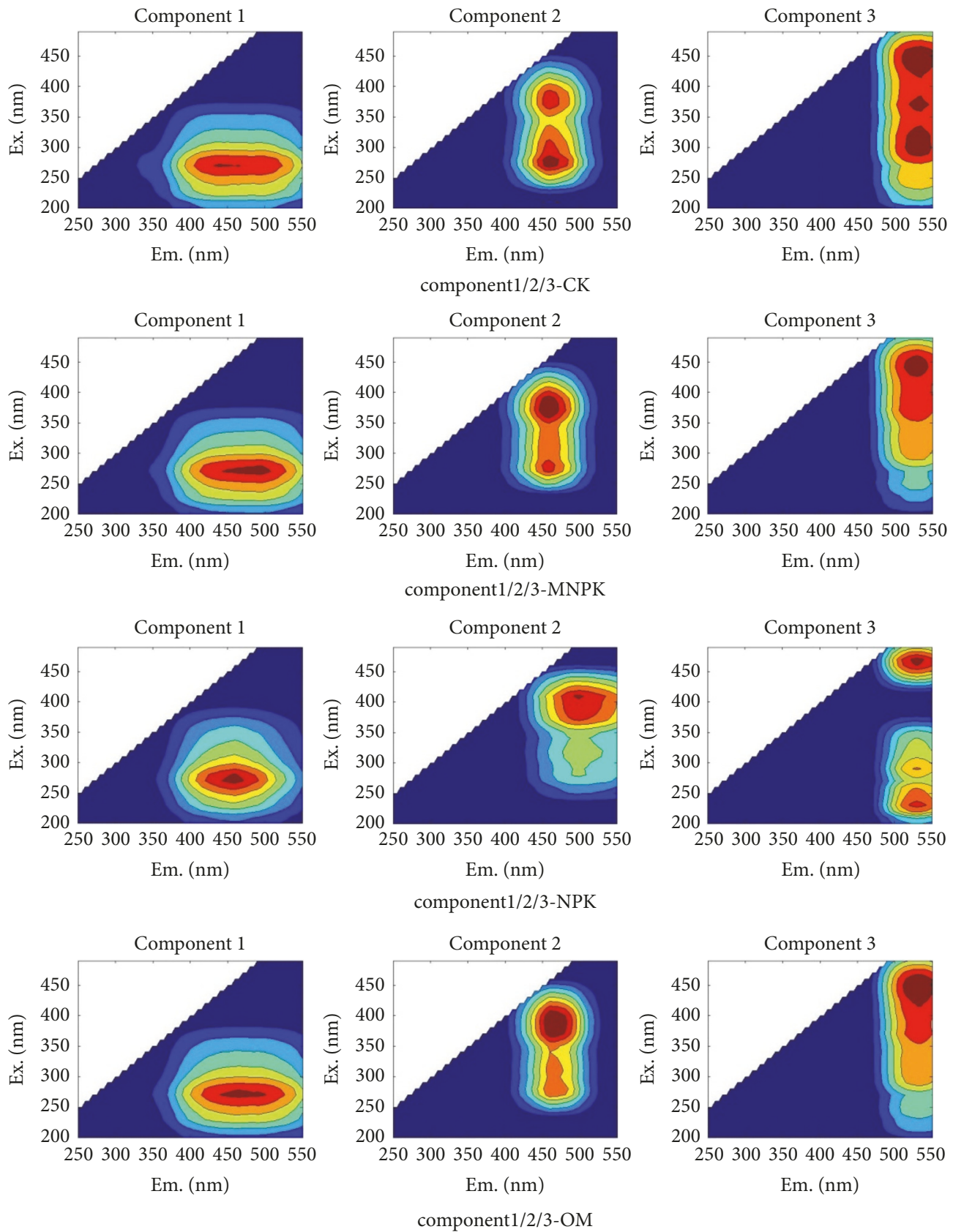

Figure 1: Fluorescence components $\mathrm{C} 1, \mathrm{C} 2$, and $\mathrm{C} 3$ after different fertilization treatments $(\mathrm{CK}=$ control, NPK= NPK fertilizer, OM=organic manure, and MNPK=manure + NPK fertilizer) identified by PARAFAC.

in Figure 1, component $\mathrm{Cl}$ exhibited a fluorescence peak at an excitation/emission wavelength pair of $270 \mathrm{~nm} / 440$ $490 \mathrm{~nm}$. Component C2 was composed of two excitation maxima at $280-320 \mathrm{~nm}$ and $380-410 \mathrm{~nm}$, both with the emission maximum at 460-500 nm. Previous studies suggested that the component is related to large molecular-sized and hydrophobic compounds $[17,18]$. Component $\mathrm{C} 3$ had excitation/emission ranges of 235, 290, and $450 \mathrm{~nm} / 530 \mathrm{~nm}$. From $\mathrm{Cl}$ to $\mathrm{C} 3$, the structure of the component became more and more complex. Although the fluorescence signal composition of humic acid under different treatments was similar, the fluorescence intensities of the various components changed with different treatments.

The maximum fluorescence intensity (Fmax) of each PARAFAC component was used to track the behaviors of the different fluorophore groups in humic acid (Figure 2). The Fmax values of components $\mathrm{C} 1$ and $\mathrm{C} 2$ in the OM, NPK, and MNPK treatments were significantly higher than those in $\mathrm{CK}$, suggesting that fertilization could improve the formation of components $\mathrm{C} 1$ and $\mathrm{C} 2$. Regarding component $\mathrm{C} 1$, the Fmax value of NPK showed the maximum in all treatments, while regarding component $\mathrm{C} 2$, there were no significant 
TABLE 1: Correlation matrix between parameters of different fluorescence characteristics.

\begin{tabular}{|c|c|c|c|c|c|c|c|}
\hline & $\mathrm{f}_{450 / 500}$ & $\mathrm{I}_{436} / \mathrm{I}_{383}$ & $\mathrm{I}_{454} / \mathrm{I}_{399}$ & FLR & HLR & $\mathrm{A}_{4} / \mathrm{A}_{1}$ & $(\mathrm{C} 2+\mathrm{C} 3) / \mathrm{C} 1$ \\
\hline $\mathrm{f}_{450 / 500}$ & 1 & -.252 & $-.722^{* *}$ & $.782^{* *}$ & $-.782^{* *}$ & $-.725^{* *}$ & $-.683^{* *}$ \\
\hline $\mathrm{I}_{436} / \mathrm{I}_{383}$ & & 1 & $.712^{* *}$ & $-.629^{* *}$ & $.629^{* *}$ & $.427^{*}$ & $.746^{* *}$ \\
\hline $\mathrm{I}_{454} / \mathrm{I}_{399}$ & & & 1 & $-.896^{* *}$ & $.896^{* *}$ & $.775^{* *}$ & $.910^{* *}$ \\
\hline FLR & & & & 1 & $-1.000^{* *}$ & $-.815^{* *}$ & $-.925^{* *}$ \\
\hline HLR & & & & & 1 & $.815^{* *}$ & $.925^{* *}$ \\
\hline $\mathrm{A}_{4} / \mathrm{A}_{1}$ & & & & & & 1 & $.781^{* *}$ \\
\hline$(\mathrm{C} 2+\mathrm{C} 3) / \mathrm{C} 1$ & & & & & & & 1 \\
\hline
\end{tabular}

$*$ and $* *$ indicate significant differences at $\mathrm{P}<0.05$ and $\mathrm{P}<0.01$, respectively.

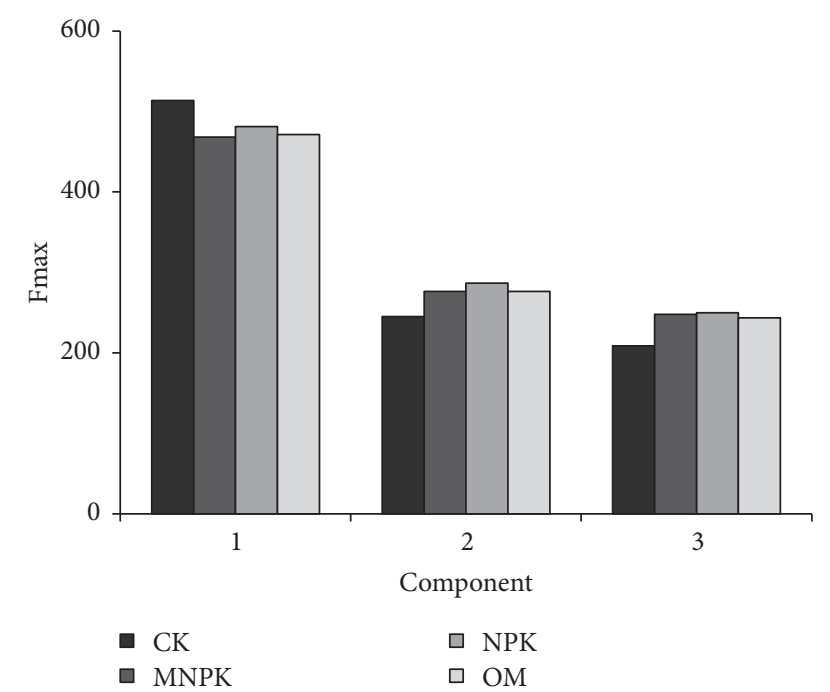

FIGURE 2: Maximum fluorescence intensity (Fmax) values of PARAFAC components $\mathrm{C} 1, \mathrm{C} 2$, and C3 under different fertilization treatments $(\mathrm{CK}=$ control, $\mathrm{NPK}=\mathrm{NPK}$ fertilizer, $\mathrm{OM}=$ organic manure, and $\mathrm{MNPK}=$ manure $+\mathrm{NPK})$.

differences in Fmax between MNPK, NPK, and OM. As for component C3, the Fmax value of MNPK was slightly higher than that of $\mathrm{CK}$, while the Fmax values of the other two treatments were slightly lower than that of CK.

3.2. Selection of Fluorescence Parameters. A number of parameters described in the Materials and Methods section, i.e., f450/500, $\mathrm{I}_{436} / \mathrm{I}_{383}, \mathrm{I}_{454} / \mathrm{I}_{399}, \mathrm{FLR}, \mathrm{HLR}, \mathrm{A}_{4} / \mathrm{A}_{1}$, and $(\mathrm{C} 2+\mathrm{C} 3) / \mathrm{C} 1$, were used to further describe the structural properties of humic acid. These parameters may reflect the changes in for example aromaticity of humic acid and its molecular weight. The correlations among the characteristics of the fluorescence spectra, including significance levels, are shown in Table 1. Although there were significant positive or negative correlations between these parameters, the information would be likely to overlap if we use these indicators for analysis directly. The methods of PCA and cluster analysis can avoid these limitations and were used to select key parameters in relation to the structure of humic acid.

The core of PCA is to extract and reduce the dimensions of data and to transform complex multiple indicators into a
TABLE 2: Characteristic values and variance contributions from the principal component analysis.

\begin{tabular}{lccc}
\hline \multirow{2}{*}{ Component } & \multicolumn{3}{c}{ Initial characteristic values } \\
& Total & Variance (\%) & Cumulative (\%) \\
\hline 1 & 5.59 & 79.9 & 79.9 \\
2 & 0.83 & 11.8 & 91.7 \\
\hline
\end{tabular}

few comprehensive indicators. The indicators can maximally retain the original data information. Normalisation in PCA eliminated the impact of the differences in orders of magnitude between the fluorescence characteristic parameters and thus made the results more balanced. Two principal components were obtained, covering $79.9 \%$ and $11.8 \%$ of the variance, respectively (Table 2); these two components thus contained most of the original index information.

$\mathrm{I}_{436} / \mathrm{I}_{383}, \mathrm{I}_{454} / \mathrm{I}_{399}, \mathrm{FLR}, \mathrm{HLR}, \mathrm{A}_{4} / \mathrm{A}_{1}$, and $(\mathrm{C} 2+\mathrm{C} 3) / \mathrm{C} 1$ were the main factors related positively to the first principal component. These factors reflected the forward process of humification; the greater the values of the indices were, the higher the degree of humification was. FLR and $f_{450 / 500}$ were the main factors related negatively to the first principal component. $\mathrm{I}_{436} / \mathrm{I}_{383}$ and $\mathrm{f}_{450} /{ }_{500}$ were related positively to the second principal component. The eigenvector of each characteristic parameter (Table 3 ) represented the degree of importance of the original index. The eigenvector value can also be used to calculate the comprehensive evaluation value of principal components.

The score values of the four treatments in each principal component (Figure 3) showed that the CK treatment had the lowest scores, which were negative in both principal components. The other three fertilization treatments showed different rankings in the first and second principal components, although all were positive: the NPK and OM treatments were higher in the first component but lower in the second component, while the opposite was the case for the MNPK treatment. The comprehensive score in the MNPK treatment was the highest, which indicated that the MNPK treatment had the greatest overall impact on the soil (Figure 3).

3.3. Clustering Analysis of Different Fertilization Treatments. Clustering analysis was used to classify the four treatment groups according to humification degree. The scores of the 
TABLE 3: Contributions of characteristic fluorescence parameters to eigenvectors of the first two principal components.

\begin{tabular}{lcc}
\hline Characteristic parameter & $\begin{array}{c}\text { Eigenvector of the first } \\
\text { principal component }\end{array}$ & $\begin{array}{c}\text { Eigenvector of the second } \\
\text { principal component }\end{array}$ \\
\hline $\mathrm{f}_{450 / 500}$ & -0.80 & 0.50 \\
$\mathrm{I}_{436} / \mathrm{I}_{383}$ & 0.70 & 0.69 \\
$\mathrm{I}_{454} / \mathrm{I}_{399}$ & 0.95 & 0.09 \\
$\mathrm{FLR}$ & -0.98 & 0.05 \\
$\mathrm{HLR}$ & 0.98 & -0.05 \\
$\mathrm{~A}_{4} / \mathrm{A}_{1}$ & 0.86 & -0.25 \\
$(\mathrm{C} 2+\mathrm{C} 3) / \mathrm{C} 1$ & 0.96 & 0.15 \\
\hline
\end{tabular}

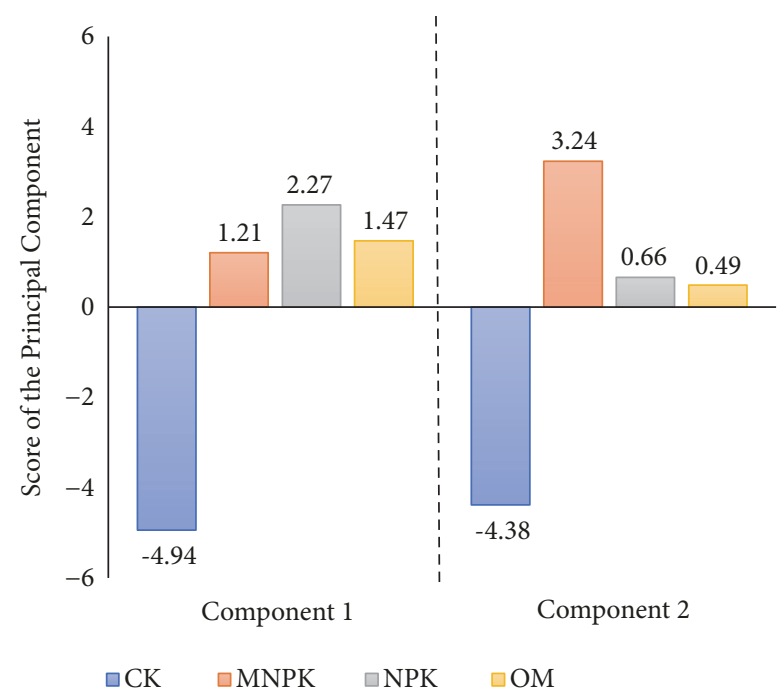

FIGURE 3: Scores of the first two principal components for different treatments. $\mathrm{CK}=$ control, $\mathrm{NPK}=\mathrm{NPK}$ fertilizer, $\mathrm{OM}=$ organic manure, and $\mathrm{MNPK}=$ manure $+\mathrm{NPK}$.

first two principal components were used as new indicators to separate the four fertilization treatments. The four treatments were divided into three groups (Figure 4(a)): (i) MNPK and OM; (ii) NPK and (iii) CK based on the changes in humification. During the fertilization process, the humification indices of A4/A1, (C2+C3)/C1, f450/f500, FLR, HLR, I436/I383, and I454/I399 changed significantly (Figures 4(b) $-4(\mathrm{~h}))$. Of these, f450/f500 and FLR showed a negative relationship with the humification degree, while the others were positive. Thus, the humification degree increased in all treatments, but there were differences between them. For A4/A1, the humification degree increased by $13.4 \%, 29.6 \%$, $18.9 \%$, and $32.7 \%$ for the treatments CK, MNPK, NPK, and $\mathrm{OM}$, respectively; i.e., the humification degree in MNPK and OM was higher than in CK and NPK. The other humification indices exhibited similar trends, except for $(\mathrm{C} 2+\mathrm{C} 3) / \mathrm{C} 1$, for which CK was almost equal to OM. Overall, the humification degree in MNPK and OM was higher than in CK and NPK. Combining this result with Figure 4(a), we can divide the treatments into three groups based on their humification degree: MNPK and OM > NPK > CK. The MNPK and OM treatments thus had the highest humification degree, which was classified as the first level. The second level was the NPK treatment and the third level was the CK treatment, which had the lowest humification compared with the other three fertilization treatments.

EEM-PARAFAC was conducted to detect the structural characteristics of humic acid under the different treatments [2]. The results shown in Figure 2 showed that treatment with MNPK, NPK, and OM significantly increased the content of $\mathrm{C} 1$ and $\mathrm{C} 2$ compared with $\mathrm{CK}$, which means that the content of large molecular-sized and hydrophobic compounds in soil increased.

The fluorescence characteristic parameters which were selected showed some correlations. This study reduced the dimensions and analysed two principal components of the fluorescence signals using PCA. The cumulative contribution was $91.5 \%$ without losing the original information. These two principal components could be related to the differences in humification. The humification indices of $\mathrm{I}_{436 / \mathrm{I} 383}, \mathrm{I}_{454 / \mathrm{I} 399}$, $\mathrm{HLR},(\mathrm{C} 2+\mathrm{C} 3) / \mathrm{C} 1$, and $\mathrm{A}_{4} / \mathrm{A}_{1}$ were the main factors influencing the first principal component positively, while $\mathrm{f}_{450 / 500}$ and FLR were the main factors influencing it negatively. The former can be considered as positive indicators and the latter as negative indicators for soil fertility. The change of the first principal component positively reflected the process of soil humification and was closely related to the structure of the soil sample. The more complex the structure of humic acids, the higher the humification degree [19].

The four treatments could be divided into three groups using clustering analysis based on the values of different humification indices: MNPK and OM were the first group; NPK was the second group; and CK was the third group. Humification indices indicated that the humification degree was highest after MNPK or OM fertilization. There were two treatments in the first level, of which MNPK fertilization led to a higher humification degree than OM fertilization. The results suggest that MNPK fertilization can solve problems of nutrient deficiency caused by OM alone or of soil acidification and compaction caused by chemical fertilization alone, so it is more effective in improving soil quality and soil fertility [20-22].

In farmland ecosystem, agricultural film, sewage, and atmospheric deposition are the main sources of microplastics in soil [23]. Microplastics in soil can adsorb organic pollutants and heavy metals in soil, but their decomposition will also pose a threat to the ecological environment [24]. 


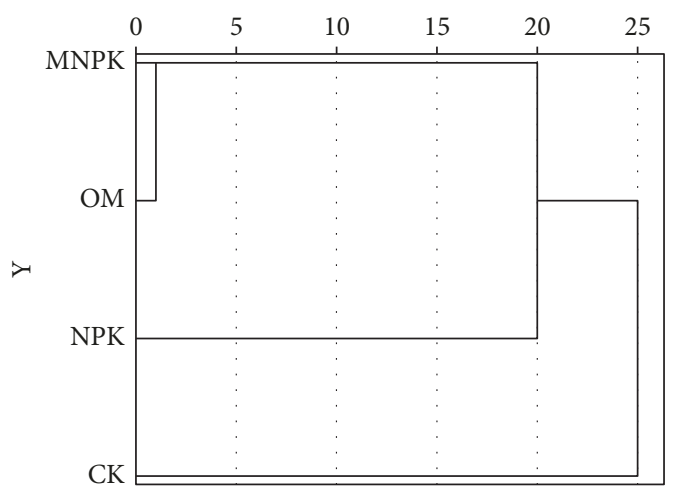

(a)

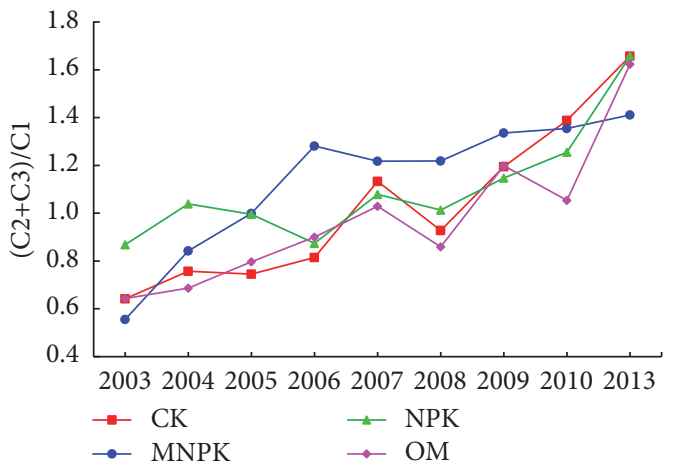

(c)

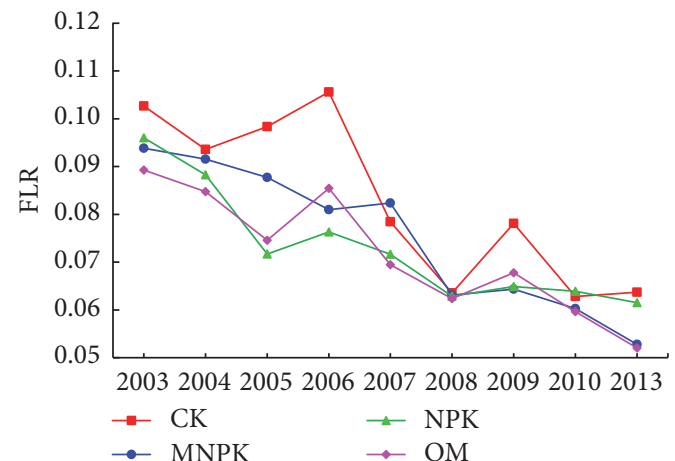

(e)

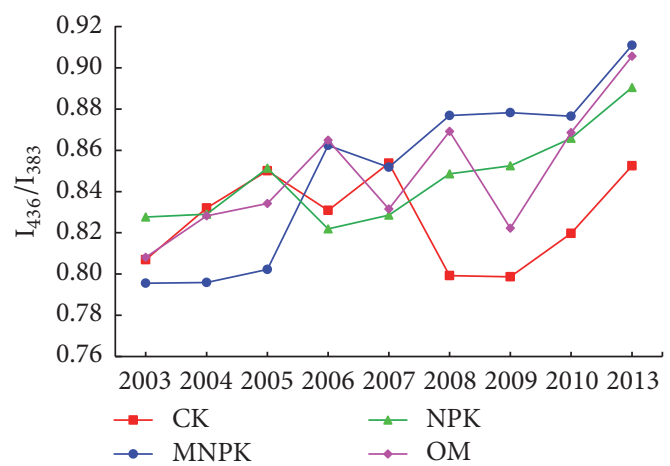

(g)

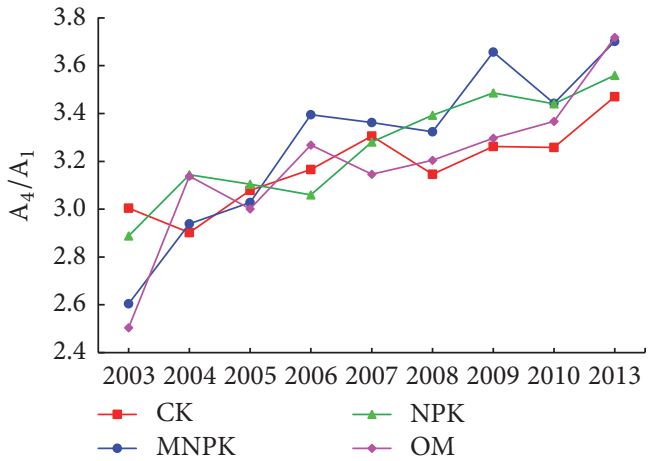

(b)

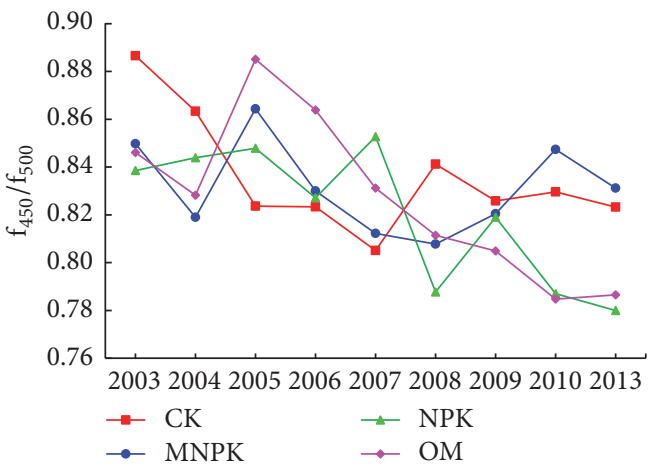

(d)

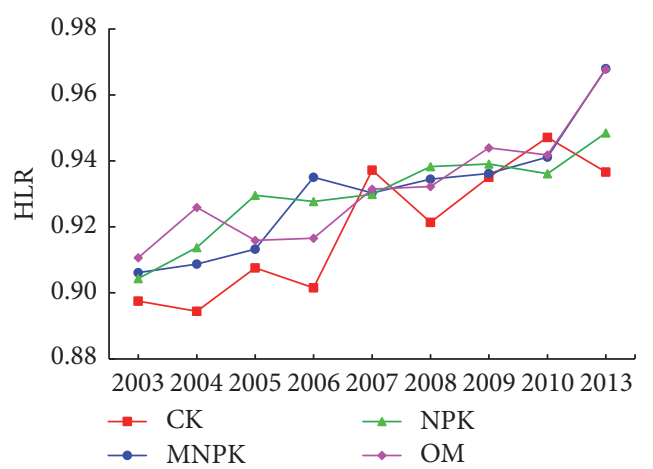

(f)

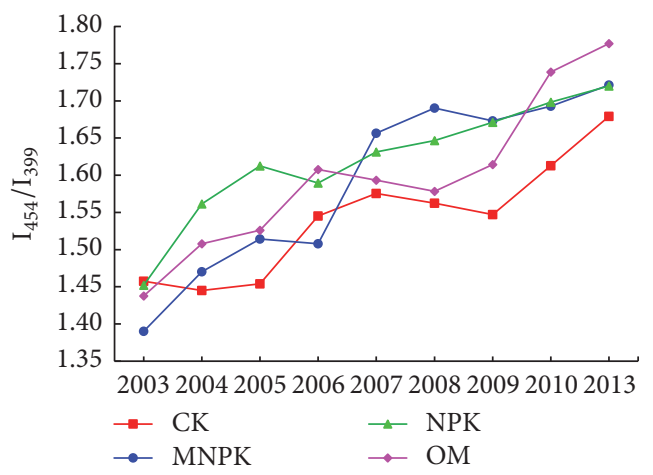

(h)

FIgURE 4: Clustering tree of the scores of the two principal components for all the field treatments (a) and the changes in humification indices ((b)-(h); see text for details). $\mathrm{CK}=$ control, NPK= NPK fertilizer, $\mathrm{OM}=$ organic manure, and MNPK=manure + NPK. 
Microplastic residues in soil caused by agricultural plastic film could significantly reduce the expression of carbon and nitrogen cycling genes in soil, decrease soil carbon and nitrogen content, and reduce soil fertility and crop yield $[25,26]$. Some studies have shown that the improvement of soil fertility can reduce the pollution of microplastics on soil and inhibit its migration in soil [27]. In this study, fertilization changed the fluorescence characteristics of soil humic acid and increased the humification degree. The increase of humus content and humification degree could increase the adsorption capacity of microplastics to heavy metals and reduce environmental pollution [28].

\section{Conclusions}

This study reduced the dimensions of six fluorescence indicators and extracted two main components using PCA. These reflected about $91.7 \%$ of the original information. EEMPARAFAC results showed that treatment with MNPK, NPK, and OM significantly increased content of large molecularsized and hydrophobic compounds in soil. Cluster analysis showed that the four treatments were divided into three levels: the first level was MNPK and OM, the second was NPK, and the third was CK. Fluorescence analysis and cluster analysis showed that MNPK and OM treatments increased the humification degree of soil humus and soil fertility and enhanced the regulation of soil on the migration and adsorption properties of microplastics. In summary, the OM or MNPK fertilization is more suitable for black soil in northeast China.

\section{Data Availability}

The data used to support the findings of this study are available from the corresponding author upon request.

\section{Conflicts of Interest}

The authors declare that they have no conflicts of interest regarding the publication of this paper.

\section{Acknowledgments}

We thank Research Professor Dr. Jihong Liu Clarke for coordination. This work was partially supported by the National Natural Science Foundation of China (41771284), National Key R\&D Plan (2018YFD0201001, 2018YFD0201004, and 2017YFD0200803), Technical system of soybean industry (CARS-04-01A), and National Natural Science Foundation of Heilongjiang (ZD2017008).

\section{References}

[1] M. Schnitzer, "Soil organic matter - the next 75 years," Soil Science, vol. 151, pp. 41-58, 1991.

[2] Y. Zhao, Y. Wei, Y. Zhang et al., "Roles of composts in soil based on the assessment of humification degree of fulvic acids," Ecological Indicators, vol. 72, pp. 473-480, 2017.
[3] J. Shi, F. Zhang, and B. Lin, "Effect of long-term fertilization on soil humus content," Soil and Fertilizer, vol. 22, pp. 15-22, 2002.

[4] Y. X. Xie, T. X. Gao, and N. C. Pan, "Assessment of multiorigin humin components evolution and influencing factors during composting," Journal of Agricultural and Food Chemistry, vol. 67, pp. 4184-4192, 2019.

[5] J. Zhang, J. Wang, T. An et al., "Effects of long-term fertilization on soil humic acid composition and structure in black soil," PLoS ONE, vol. 12, article e0186918, 2017.

[6] W. von Mersi and F. Schinner, "An improved and accurate method for determining the dehydrogenase activity of soils with iodonitrotetrazolium chloride," Biology and Fertility of Soils, vol. 11, no. 3, pp. 216-220, 1991.

[7] X. Q. Zhang, H. Chen, Y. Q. Qiao et al., "Effects of longterm different fertilization models on number of culturable microorganisms and enzyme activities in shajiang black soil," Ecology and Environmental Sciences, vol. 25, no. 8, pp. 12831290, 2016.

[8] L. Zhihong, J. Suxia, Z. Meiliang et al., "Effects of long-term located fertilization on the contents and composition of organic matter in paddy soil," Agricultural Science \& Technology, vol. 16, no. 10, pp. 2238-2242, 2015.

[9] X. Y. Hao, X. Z. Ma, B. K. Zhou et al., "Sequestration effect of organic carbon in black soil under long-term different fertilization measures," Journal of Soil and Water Conservation, vol. 30, no. 5, pp. 316-321, 2016 (Chinese).

[10] X. D. Wang, Y. P. Zhang, J. Lü et al., "Studies on photosynthesis in flag leaves and its relation to grain filling course of high yield wheat," Scientia Agricultura Sinica, vol. 33, no. 6, pp. 75-81, 2000 (Chinese).

[11] G. Wang and W. J. Zhao, "Principal components and cluster analysis of main agronomic characters of sweet sorghum germplasm resources," Journal of Agriculture, vol. 9, no. 5, pp. 1-9, 2019 (Chinese).

[12] S. P. Hu, Z. J. Su, X. F. Yu et al., "Component analysis and fuzzy clustering of drought resistance related characters of maize inbred lines," Agricultural Research in the Arid Areas, vol. 34, no. 6, pp. 81-88, 2016 (Chinese).

[13] J. Wu, Y. Zhao, W. Zhao et al., "Effect of precursors combined with bacteria communities on the formation of humic substances during different materials composting," Bioresource Technology, vol. 226, pp. 191-199, 2017.

[14] H.-Y. Cui, Y. Zhao, Y.-N. Chen et al., "Assessment of phytotoxicity grade during composting based on EEM/PARAFAC combined with projection pursuit regression," Journal of Hazardous Materials, vol. 326, pp. 10-17, 2017.

[15] J. Wu, Y. Zhao, H. Qi et al., "Identifying the key factors that affect the formation of humic substance during different materials composting," Bioresource Technology, vol. 244, pp. 1193-1196, 2017.

[16] W. Guo, J. Xu, J. Wang, Y. Wen, J. Zhuo, and Y. Yan, "Characterization of dissolved organic matter in urban sewage using excitation emission matrix fluorescence spectroscopy and parallel factor analysis," Journal of Environmental Sciences, vol. 22, no. 11, pp. 1728-1734, 2010.

[17] S. K. L. Ishii and T. H. Boyer, "Behavior of reoccurring parafac components in fluorescent dissolved organic matter in natural and engineered systems: A critical review," Environmental Science \& Technology, vol. 46, no. 4, pp. 2006-2017, 2012.

[18] L. Zhu, Y. Zhao, Y. Chen et al., "Characterization of atrazine binding to dissolved organic matter of soil under different types 
of land use," Ecotoxicology and Environmental Safety, vol. 147, pp. 1065-1072, 2018.

[19] Z. Wei, X. Zhang, Y. Wei et al., "Fractions and biodegradability of dissolved organic matter derived from different composts," Bioresource Technology, vol. 161, pp. 179-185, 2014.

[20] P. Schjønning, B. F. Christensen, and B. Carstensen, "Physical and chemical properties of a sandy loam receiving animal manure, mineral fertilizer or no fertilizer for 90 years," European Journal of Soil Science, vol. 45, pp. 257-268, 1994.

[21] L. Bi, B. Zhang, G. Liu et al., "Long-term effects of organic amendments on the rice yields for double rice cropping systems in sub-tropical China," Agriculture, Ecosystems \& Environment, vol. 129, pp. 534-541, 2009.

[22] Y. Bao, M. Xu, F. Lü et al., "Evaluation method on soil fertility under long-term fertilization," Scientia Agricultura Sinica, vol. 45, no. 21, pp. 4197-4204, 2012.

[23] A. A. Horton, A. Walton, D. J. Spurgeon, E. Lahive, and C. Svendsen, "Microplastics in freshwater and terrestrial environments: Evaluating the current understanding to identify the knowledge gaps and future research priorities," Science of the Total Environment, vol. 586, pp. 127-141, 2017.

[24] J. Talvitie, A. Mikola, O. Setälä, M. Heinonen, and A. Koistinen, "How well is microlitter purified from wastewater? - A detailed study on the stepwise removal of microlitter in a tertiary level wastewater treatment plant," Water Research, vol. 109, pp. 164172, 2017.

[25] H. Qian, M. Zhang, G. Liu et al., "Effects of soil residual plastic film on soil microbial community structure and fertility," Water Air \& Soil Pollution, vol. 229, no. 8, article 261, 2018.

[26] Z. G. Wang, Y. M. You, W. H. Xu et al., "Dimethyl phthalate altered the microbial metabolic pathways in a Mollisol," European Journal of Soil Science, vol. 69, no. 3, pp. 439-449, 2018.

[27] Y. G. Zhu, D. Zhu, T. Xu et al., "Effects of plastic pollution on soil ecosystem: progress and consideration," Journal of Agricultural Environmental Sciences, vol. 38, no. 1, pp. 1-6, 2019 (Chinese).

[28] J. W. Pang, Study on the Carrier Mechanism of Microplastics to Typical Pollutants [Master thesis], Anhui University of Technology, 2018 (Chinese). 


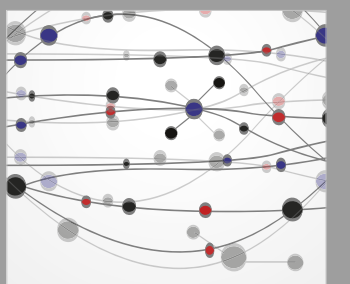

The Scientific World Journal
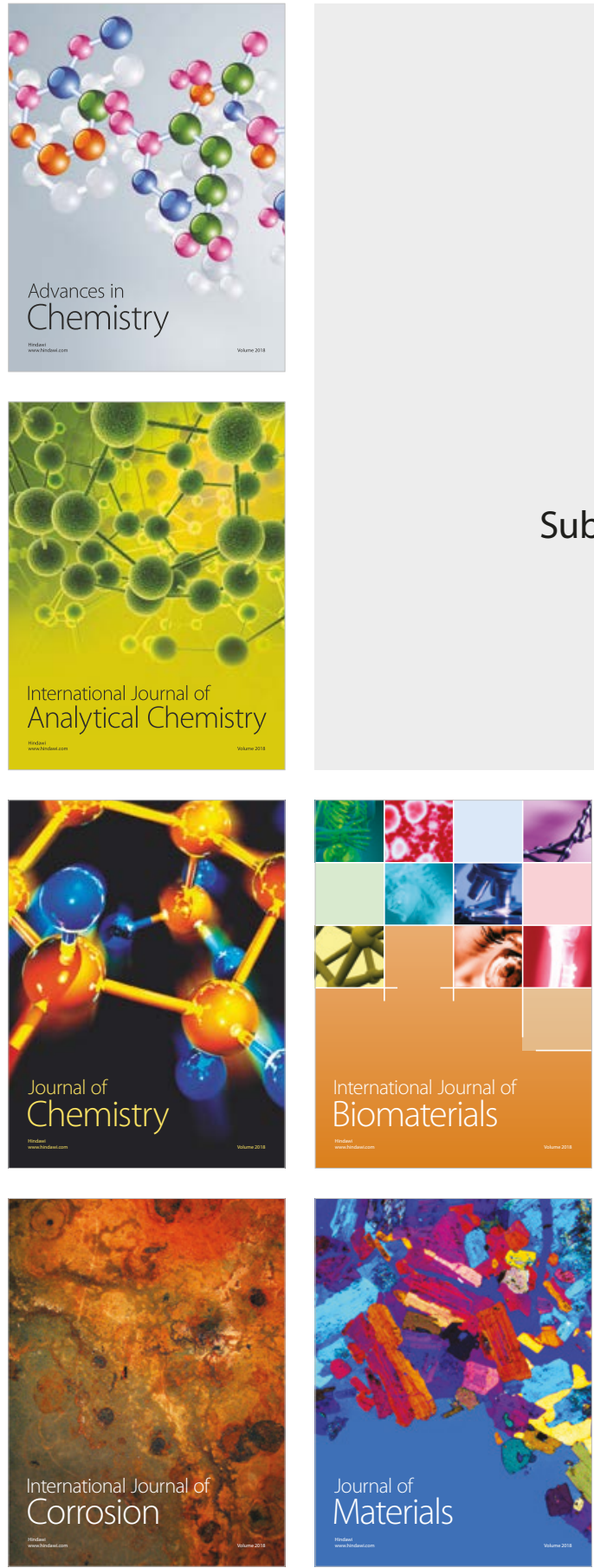

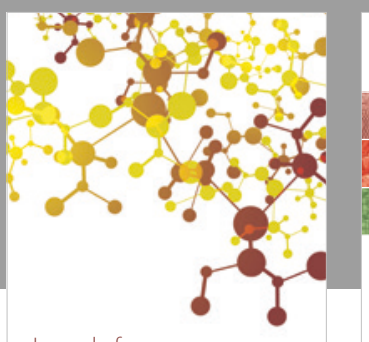

Journal of

Applied Chemistry
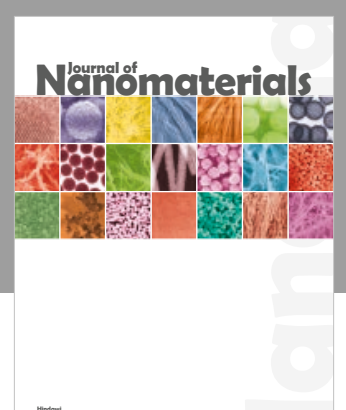

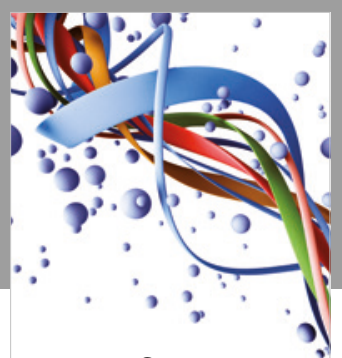

Scientifica

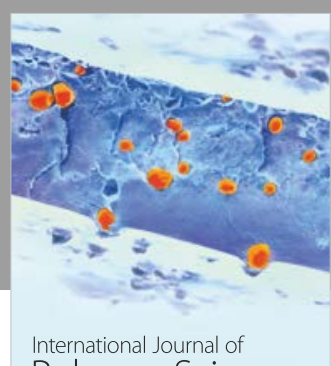

Polymer Science

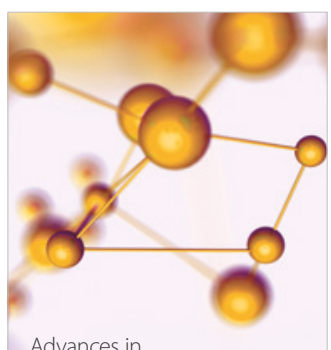

Physical Chemistry
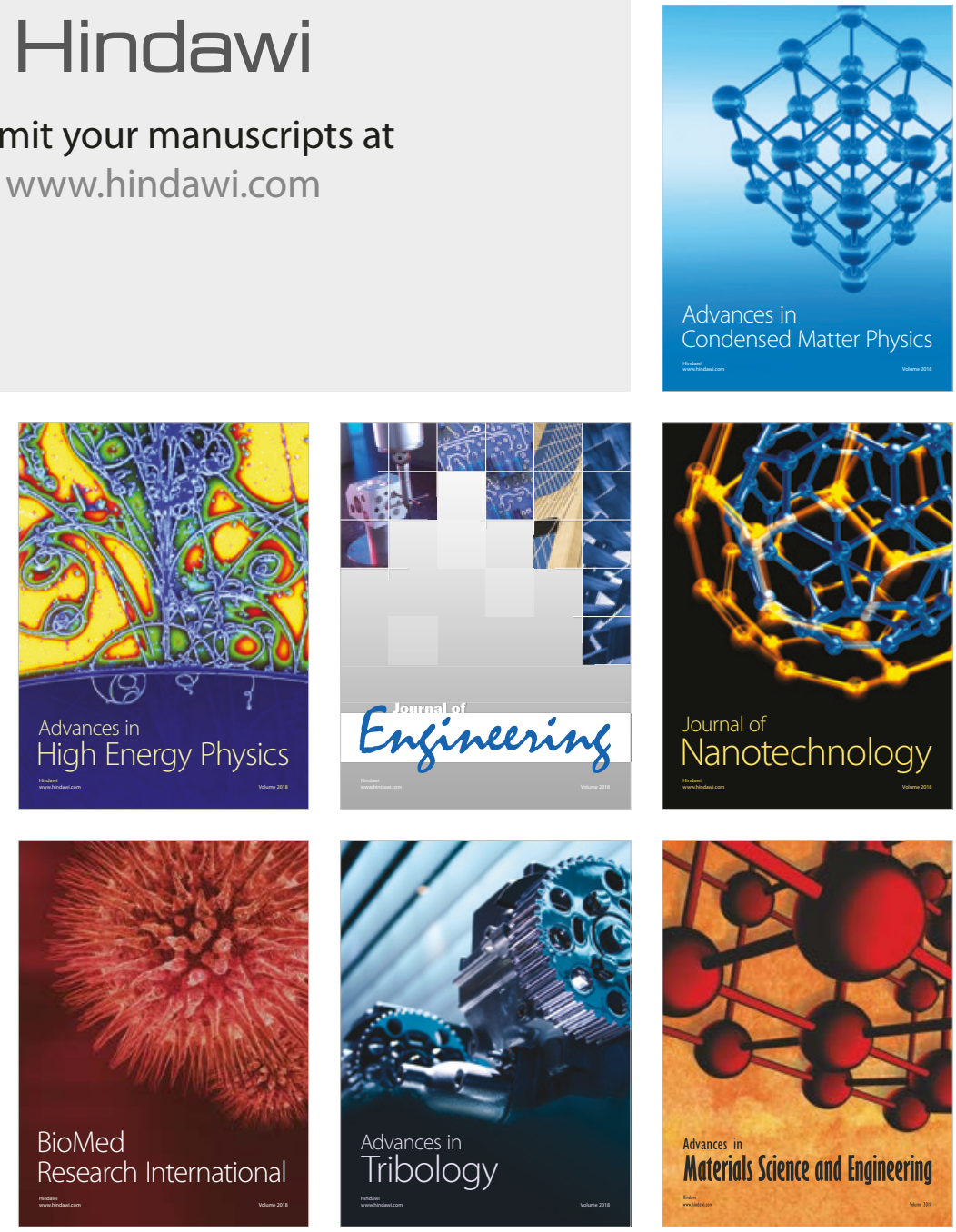